\title{
Optimization of the Recovery of Anthocyanins from Chokeberry Juice Pomace by Homogenization in Acidified Water
}

\author{
Maria Cinta Roda-Serrat ${ }^{1}$. Thalles Allan Andrade ${ }^{1}$ Janus Rindom ${ }^{1} \cdot$ Peter Brilner Lund ${ }^{1}$. Birgir Norddahl ${ }^{1}$. \\ Massimiliano Errico ${ }^{1}$
}

Received: 10 February 2020 / Accepted: 13 June 2020 / Published online: 20 June 2020

(c) Springer Nature B.V. 2020

\begin{abstract}
The recovery efficiency of waste valorization processes depends on an interplay of different conditions that are sometimes overlooked. Process optimization by the means of establishing mathematical relations between the process parameters and outputs is a strong tool to identify optimal operating conditions based on experimental data. In this study, the extraction of anthocyanins from chokeberry (Aronia melancocarpa) juice pomace using homogenization in acidified water was selected as a case study for process optimization using response surface methodology. The parameters studied were the citric acid content in the water, the temperature and the liquid-solid ratio. The optimal conditions to maximize both anthocyanin concentration and total anthocyanin content extracted were $1.5 \mathrm{wt} \%$ citric acid, $45^{\circ} \mathrm{C}$ and $34 \mathrm{~g}$ solvent $/ \mathrm{g}$ fresh pomace. Furthermore, the model developed predicted satisfactorily the overall anthocyanin content and anthocyanin concentration in the extract, as well as the final $\mathrm{pH}$ and total dissolved solids. The process optimization performed in this study sets the ground for further process design targeting the production of high-value products from byproducts or biowaste to be used in food ingredients or supplements.
\end{abstract}

\section{Graphic Abstract}

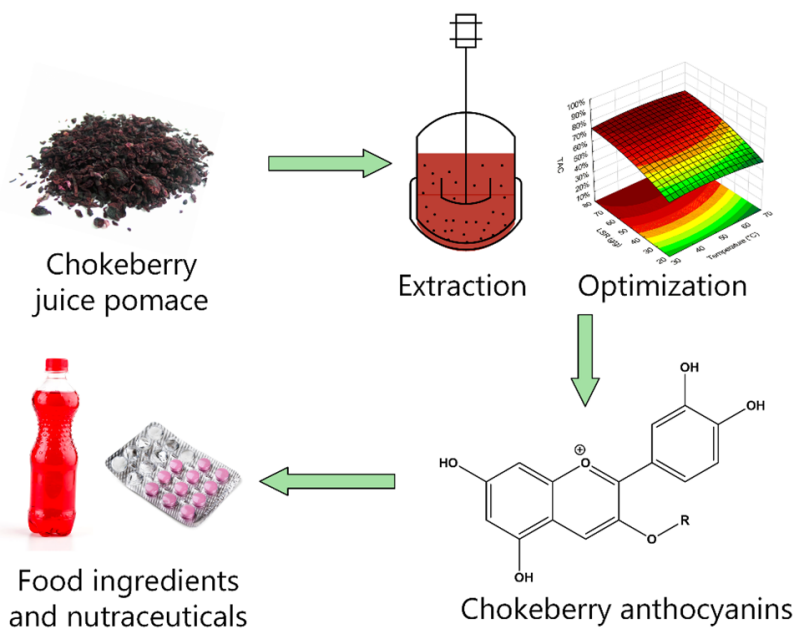

Keywords Aronia melanocarpa $\cdot$ Extraction $\cdot$ Polyphenol $\cdot$ Bioactive $\cdot$ By-product $\cdot$ Valorization

Electronic supplementary material The online version of this article (https://doi.org/10.1007/s12649-020-01127-w) contains supplementary material, which is available to authorized users.

Extended author information available on the last page of the article 


\section{Statement of Novelty}

Many by-products and biowaste from the food and beverage industry are excellent sources for the recovery of highvalue components. This research work presents a case study for the valorization of chokeberry (Aronia melanocarpa) juice pomace in order to produce extracts rich in bioactive natural pigments. This study presents a sustainable approach to extraction by homogenization of the plant material in acidified water. Based on experimental data, the extraction conditions were optimized using mathematical tools, and a model was built in order to predict the characteristics of the final product. A better understanding of the process conditions and their influence in the final product is of paramount importance for the design of successful recovery processes.

\section{Introduction}

The label natural, especially when associated with food, supplements or drugs, is becoming essential for most consumers. After decades looking for underground resources, mainly non-renewable, human beings are rediscovering the potential of plant extracts in human nutrition and health. The major goal of plant-based dietary supplements is to maintain or improve the overall health condition, prevent chronic diseases, and to fill the nutritional gap of daily diet [1]. Following the COVID-19 world pandemic, nutraceuticals have recently been in the spotlight as potential therapeutic compounds against RNA viruses like influenza and coronavirus $[2,3]$. The possibility of reducing the risk of developing various diseases by using supplements has created a multibillion-dollar industry $[4,5]$. The expected growth in demand in the coming years sets the interest in defining improved and economically competitive methods to produce natural bioactives that can be used as food ingredients and nutraceuticals.

Fruit and vegetable processing waste has an untapped potential as a source of specific bioactive compounds ranging from proteins to essential fatty acids and polyphenols [6-8]. In Europe, juice production residue ranks as the 5th main contributor to the total yearly food waste, accounting for approximately $3 \%$ of the total weight disposed [9]. This waste is nowadays mainly used as livestock feed, soil fertilizer, for the production of biofuels or discarded in landfilling [10]. Recovery of bioactives from food processing waste thus appears as an attractive opportunity that has received attention in recent years [11-13].

Black chokeberry (Aronia melanocarpa) is a perennial shrub that produces small dark berries with a very high polyphenol content. Their health-promoting effect was already known by Native Americans for the treatment of cold [14], but since then many other effects have been discovered. According to literature, the strong antioxidative properties of chokeberries may be effective in the treatment of health disorders related with oxidative stress and cancers $[15,16]$. Other effects under investigation are anti-inflammatory effects used for the protection of blood vessels [17], antibacterial activity [18], prevention and treatment of noncommunicable diseases [19], decrease of the risk of diabetes and increase effectiveness of insulin [20]. To this great interest in the effects on human health corresponds the increasing focus on the study of the bioactive compounds in chokeberry and its processing byproducts [21].

In the extensive review from Denev et al. [22] chokeberry fruits, juices and concentrates are reported as rich sources of proanthocyanidins, anthocyanins, flavonols, flavan-3-ols and hydroxycinnamic acids. Kapci et al. [23] reported total phenolics, flavonoids and anthocyanins in a variety of chokeberry products including the fruit, juice, concentrate and pomace, and observed that the pomace had the highest content in dry weight basis. Some research works have focused on pomace valorization targeting the extraction of total phenolics, commonly quantified as gallic acid equivalents [24-26]. Among polyphenols, anthocyanins are perhaps the subgroup that has attracted more interest due to their many applications either as bioactives or natural colors $[27,28]$. Table 1 shows an overview of the research works dedicated to the extraction of anthocyanins from chokeberry juice pomace.

The anthocyanin extraction yields reported for chokeberry pomace are mostly within the range of $5-20 \mathrm{mg} / \mathrm{g}$ DW (dry weight basis) with few exceptions in the higher range of $66-115 \mathrm{mg} / \mathrm{g}$ DW. It is important to note that the juice production methodology influences the composition of the pomace and its potential. Vagiri and Jensen [29] compared the pomace obtained by different juice production methods and observed anthocyanin yields of $1.14 \mathrm{mg} / \mathrm{g} \mathrm{FW}$ (fresh weight basis) for pomace obtained after enzymatic treatment followed by hot pressing $\left(50{ }^{\circ} \mathrm{C}\right)$; and $1.86 \mathrm{mg} / \mathrm{g} \mathrm{FW}$ when the pomace was produced by cold pressing $\left(2{ }^{\circ} \mathrm{C}\right)$. Oszmiański and Lachowicz (2016) [30] reported yields in pomace obtained from crushed and uncrushed berries of 66.5 and $115.7 \mathrm{mg} / \mathrm{g}$ DW, respectively. As it could be expected, the pomaces obtained in milder juice processing conditions retain a larger fraction of the anthocyanins, and thus can reach higher absolute yields in the recovery step. The comparison of different extraction techniques should bear this information in mind in order to be fair to the maximum potential of any given feedstock.

The extraction solvent is typically selected according to the polarity of the target component, in order to maximize the solubility and mass transfer. As shown in Table 1, alcohols and alcohol-water mixtures are the preferred solvents. However, from a processing perspective that needs to be 


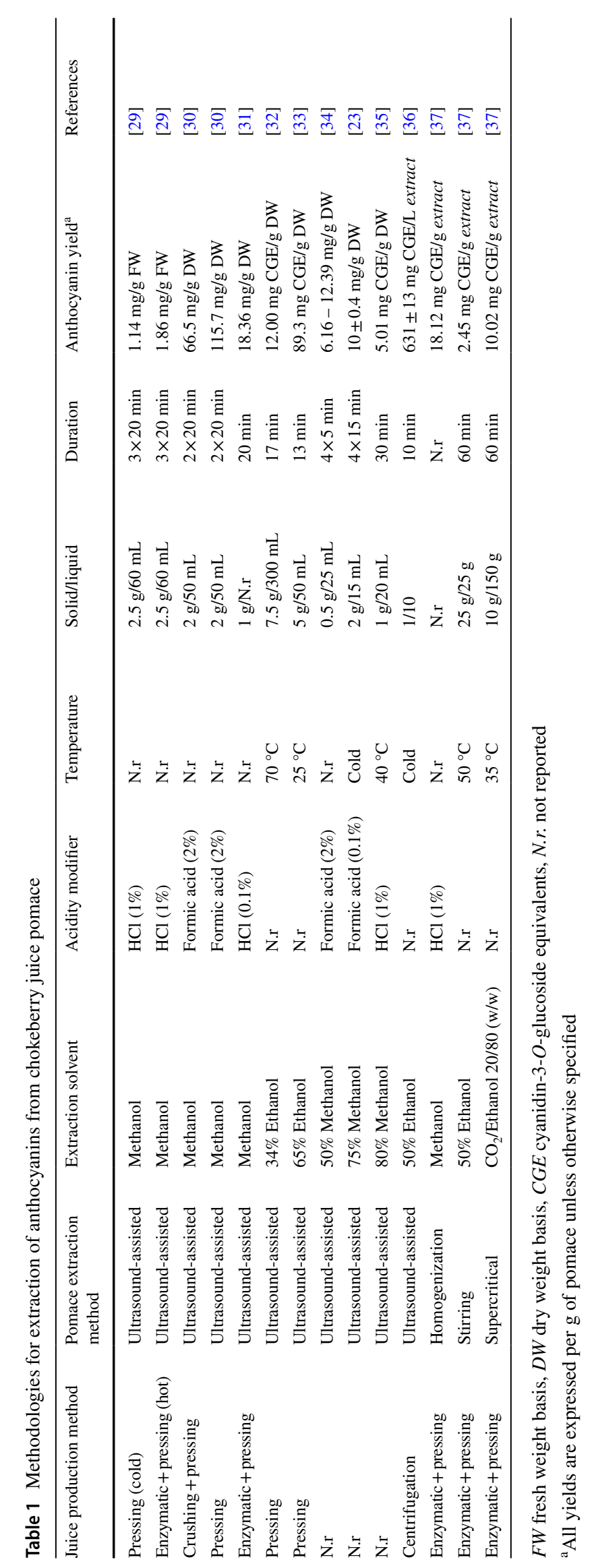


upscaled to produce food ingredients or dietary supplements, water remains the safest, cheapest, most readily available and environmentally friendly option.

Most of the research works reported in Table 1 have been dedicated to the ultrasound-assisted extraction (UAE) of chokeberry pomace. D'Alessandro et al. [32] explored the UAE process in the following conditions: solvent: $0-50 \%$ ethanol $(\mathrm{v} / \mathrm{v})$; temperature: $20-70{ }^{\circ} \mathrm{C}$; sonication power: 0-100 W; and duration: $0-4 \mathrm{~h}$. In their study, they report an optimum yield of $12.0 \mathrm{mg}$ cyanidin-3- $O$-glucoside equivalents (CGE)/g DW at $34 \%$ ethanol, $70{ }^{\circ} \mathrm{C}, 100 \mathrm{~W}$, and $17 \mathrm{~min}$. Extended treatment resulted in anthocyanin degradation, which occurred at all temperatures higher than $45^{\circ} \mathrm{C}$. In the same study, they emphasize that if the use of ethanol or heating is not desired, the same yield can be reached using water at $20^{\circ} \mathrm{C}$ for 55 or $184 \mathrm{~min}$, with and without sonication, respectively. The poor thermal stability of anthocyanins is well-known. Sui et al. [38] tested the stability of anthocyanin aqueous solutions stored at temperatures in the range of 4 to $65{ }^{\circ} \mathrm{C}$ and observed that higher temperatures were detrimental to anthocyanin preservation. Mauricio et al. [39] observed degradation of anthocyanins during decoction of sour cherry liquor pomace at $100{ }^{\circ} \mathrm{C}$ and recommended to keep the extraction process temperature at $25^{\circ} \mathrm{C}$.

Wozniak et al. [37] compared three different extraction methodologies: homogenization in methanol, stirring in 50\% ethanol and supercritical $\mathrm{CO}_{2}$ extraction; and reported anthocyanin yields of $18.12,2.45$ and $10.02 \mathrm{mg}$ $\mathrm{CGE} / \mathrm{g}$ extract, respectively. Homogenization in methanol showed a superior performance, probably because the extraction was repeated 5 times with fresh solvent on the same material. In the same study, supercritical $\mathrm{CO}_{2}$ extraction required of large amounts of ethanol as co-solvent $(80 \% \mathrm{w} / \mathrm{w})$ in order to increase the polarity of the solvent mixture. Dulf et al. [35] evaluated extractability of anthocyanins in chokeberry pomace after solid phase fermentation with two different microbial cultures incubated at $\mathrm{pH}$ 5.5. The anthocyanin yield increased from $5.01 \mathrm{mg} \mathrm{CGE} / \mathrm{g}$ DW to 6.1 and $5.9 \mathrm{mg} \mathrm{CGE} / \mathrm{g}$ DW when using cultures of Rhizopus oligosporus and Aspergillus niger, respectively. The maximum yields were observed upon 2 days incubation, after which the yields decreased.

Anthocyanins are known to be more stable in slightly acidic media. Ekici et al. [40] studied the stability of extracts obtained from red cabbage, black carrot and grape in the $\mathrm{pH}$ range from 3.0 to 7.0 ; and observed that anthocyanins were more stable in the lower $\mathrm{pH}$ range. Howard et al. [41] tested the stability of anthocyanins in chokeberry juice at the $\mathrm{pH}$ levels of 2.8, 3.2 and 3.6 and observed that in this range the stability also increased with acidity level, however to a minor extent. Most of the works reported in Table 1 use formic acid or hydrochloric acid as acidity modifiers. In the present study, the acidification of the solvent was performed by addition of citric acid, a colorless, odorless, water-soluble and non-toxic polycarboxylic acid commonly used in foods, beverages and pharmaceuticals [42].

Most of the studies reported in Table 1 performed the extractions at a constant value of liquid-solid ratio. However, the characteristics of the final extract are also affected by the amount of solvent used in the process. In general, the use of large liquid-solid ratios results in higher amounts of total product extracted. However, the extracts produced can become very diluted, while at the same time the total amount of buffer salts or acidity modifiers in the final product rises to an unrealistic level.

Besides the extraction techniques already mentioned, other methodologies have been reported in the literature to aid in the recovery of bioactives, including microwave heating [43], combination of high temperature and pressure [44], electroporation [45] or enzymatic treatment [46]. As discussed above, given the particularity of anthocyanins and their stability, a thorough examination of the process conditions and their relationship is key for the successful implementation of the recovery process.

The present study focuses on the identification of the optimal operative conditions for the sustainable extraction of anthocyanins from chokeberry juice production waste using homogenization and extraction in aqueous citric acid. The conditions studied are the citric acid content in water, temperature and liquid-solid ratio. Response surface methodology was used to construct an empirical model that relates the process factors to the observed responses. The empirical model was then used to identify the maximal predicted responses, which are discussed from a process-oriented perspective. Furthermore, the selected set of process conditions was replicated in the laboratory and compared with the predicted results. The aim of this study is not only to provide an optimum for the recovery process in laboratory scale, but also to open the discussion on the suitability of the different sets of conditions in the production of bioactives.

\section{Materials and Methods}

\section{Plant Material}

Black chokeberry (Aronia melanocarpa) pomace obtained by cold pressing was provided by the juice production facility Elkærholm (Egtved, Denmark) in November 2017. After the pressing step, the pomace (moisture content $65 \pm 1 \mathrm{wt} \%$ ) was immediately stored at $-20{ }^{\circ} \mathrm{C}$ and thawed at $5{ }^{\circ} \mathrm{C}$ before processing. 


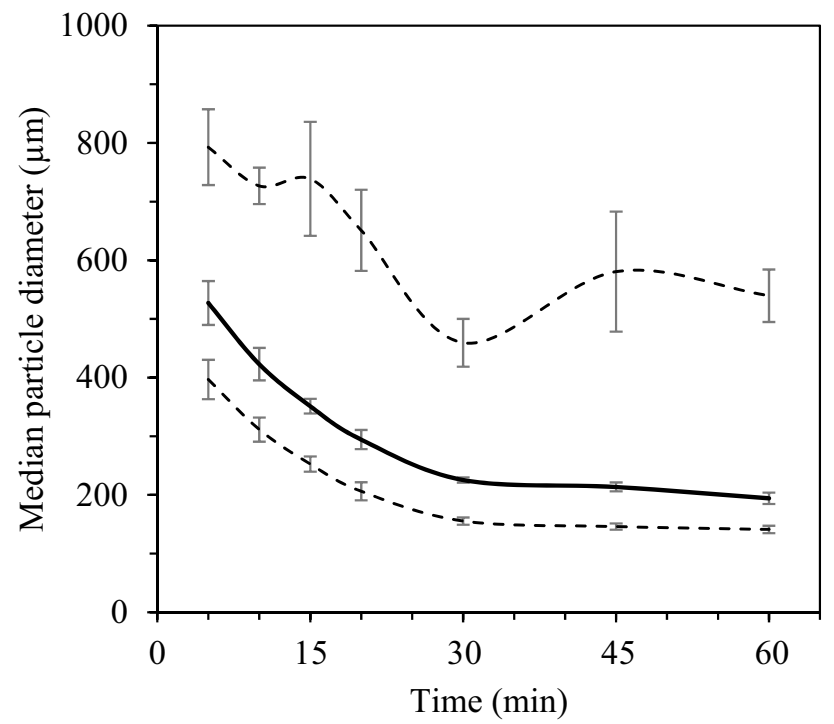

Fig. 1 Median particle size of the suspension during homogenization (full line). The dashed lines illustrate the interval of particle diameters where $80 \%$ of the particles are found. Operating conditions: CA: 0.75\%; T: $50{ }^{\circ} \mathrm{C}$; LSR $50 \mathrm{~g} / \mathrm{g}$

\section{Chemicals and Reagents}

Exhaustive extractions were performed using analytical grade methanol (VWR Prolabo, Søborg, Denmark) and $37 \%$ v/v hydrochloric acid (Sigma Aldrich, Søborg, Denmark). Aqueous extraction media were prepared using demineralized water and citric acid monohydrate $(99.5 \% \mathrm{w} / \mathrm{w})$ (Sigma Aldrich, Brøndby, Denmark). HPLC eluents were prepared using milliQ water (ELGA PureLab ${ }^{\circledR}$ Chorus, Glostrup, Denmark), analytical grade trifluoroacetic acid (Sigma Aldrich, Søborg, Denmark), and HPLC grade acetonitrile (VWR Prolabo, Søborg, Denmark). Cyanidin-3-Ogalactoside $(\geq 97 \%)$, cyanidin-3-O-glucoside $(\geq 96 \%)$ and cyanidin-3-O-arabinoside $(\geq 95 \%)$ were purchased from Extrasynthese (Genay, France).

Table 2 Experimental design for the 3-level-3-factor response surface analysis

\begin{tabular}{lllll}
\hline Factor & Abbreviation & Level & & \\
\cline { 3 - 5 } & & Low & Center & High \\
\hline Temperature $\left({ }^{\circ} \mathrm{C}\right)$ & $\mathrm{T}$ & 30 & 50 & 70 \\
Liquid-solid ratio $(\mathrm{g} / \mathrm{g})$ & $\mathrm{LSR}$ & 20 & 50 & 80 \\
Citric acid $(\mathrm{wt} \%)$ & $\mathrm{CA}$ & 0.25 & 0.75 & 1.5 \\
\hline
\end{tabular}

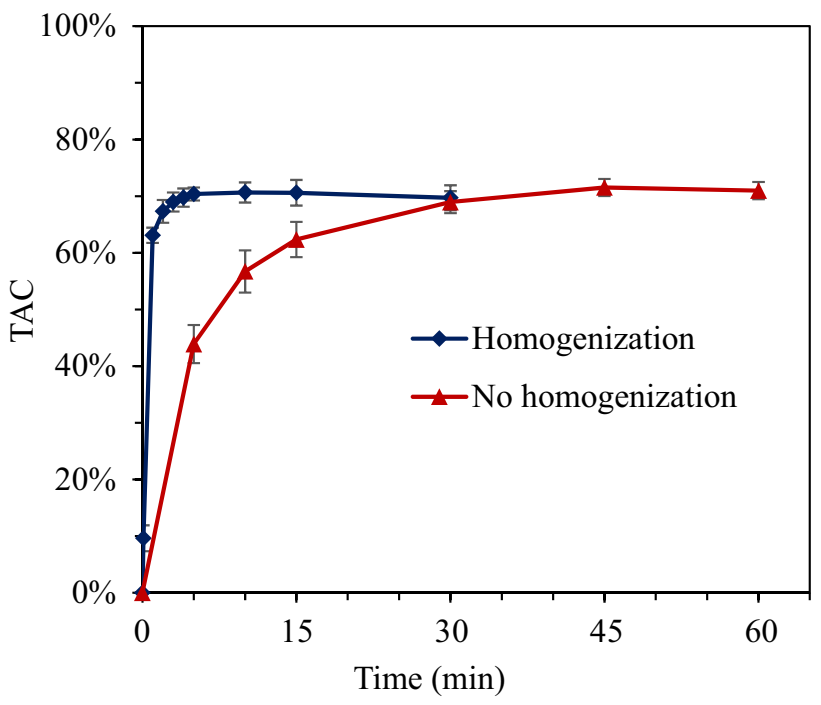

Fig. 2 Total anthocyanin content (TAC) extracted with and without homogenization, with respect to time. Operating conditions: CA: $0.75 \mathrm{wt} \%$; T: $50{ }^{\circ} \mathrm{C}$; LSR $50 \mathrm{~g} / \mathrm{g}$

\section{Exhaustive Extraction Process with Acidified Methanol}

Total extractable anthocyanin in chokeberry pomace was assessed following the process reported by Dinkova et al. [47] with minor modifications. Shortly, $500 \mathrm{mg}$ of thawed pomace were suspended in $15 \mathrm{~mL}$ acidified methanol $(1 \%$ $\mathrm{HCl} \mathrm{v/v).} \mathrm{The} \mathrm{mixture} \mathrm{was} \mathrm{vortexed} \mathrm{for} 10 \mathrm{~s}$, homogenized in an UltraTurrax T18 (IKA, Aarhus, Denmark) for $5 \mathrm{~min}$, sonicated for $20 \mathrm{~min}$, and finally centrifuged $(5000 \mathrm{rpm}$, $22{ }^{\circ} \mathrm{C}, 5 \mathrm{~min}$ ). The supernatant was collected, and the pellet was re-extracted with two more portions of $15 \mathrm{~mL}$ acidified methanol. The resulting supernatants were pooled together, brought up to $100 \mathrm{~mL}$, and analyzed. The anthocyanin content obtained was taken as a reference for $100 \%$ total anthocyanin content (TAC) in the pomace (Fig. 1).

\section{Extraction with Citric Acid Aqueous Solution}

The aqueous extractions were performed in batch mode on $1 \mathrm{~L}$ jacketed glass extractors coupled to an external thermostatic bath. $1000 \mathrm{~mL}$ solvent were heated to the desired temperature shown in Table 2 and the pomace was added. The extraction mixture was then homogenized using an UltraTurrax T18 (IKA, Aarhus, Denmark) operated at $9500 \mathrm{rpm}$ for $30 \mathrm{~min}$. The homogenization treatment allowed mixing and re-circulation of the particles in suspension in the extraction liquid. Sampling was performed at regular time intervals, as shown in Fig. 2, by pipetting $10 \mathrm{~mL}$ aliquots from middle depth in the reactor, in order to ensure that the sample was well mixed and representative of the whole 
system. A control extraction test without homogenization was performed for $60 \mathrm{~min}$. The samples collected were centrifuged $\left(5000 \mathrm{rpm}, 22{ }^{\circ} \mathrm{C}, 5 \mathrm{~min}\right)$ and the supernatant was further analyzed for total anthocyanin content, $\mathrm{pH}$ and total dissolved solids.

The experimental plan followed a face-centered central composite design with three factors and three levels, requiring a total of 15 experiments. The experiments were performed in random order in three individual replicates $(n=3)$ and the results are shown as mean \pm standard deviation. The factors and levels tested are shown in Table 2. The range of temperatures (T) selected was $30-70{ }^{\circ} \mathrm{C}$ following literature data for optimal extractability and minimum degradation of anthocyanins as summarized in Table 1 . The ranges of liquid-solid ratios (LSR) and citric acid content (CA) were selected based on the following constraints: (1) that the $\mathrm{pH}$ of the mash should be $\leq 3.0$ for stability reasons, and (2) that the weight ratio of citric acid added and total anthocyanins in the extract should be $\leq 50$, in order to give a realistic boundary.

\section{Analytical Methods}

\section{Quantification of Anthocyanins}

Anthocyanins were quantified by high-performance liquid chromatography (HPLC) (HP 1200 series, Agilent Technologies Aps, Nærum, Denmark) equipped with a photodiode array detector. The stationary phase was a $\mathrm{C} 18$ column (Gemini $5 \mu$ C18 110A, 250×4.6 mm i.d., Phenomenex Aps, Værløse, Denmark) operated at $25^{\circ} \mathrm{C}$. The mobile phase was a gradient of $0.05 \%$ trifluoroacetic acid in water (solvent $\mathrm{A}$ ) and $0.05 \%$ trifluoroacetic acid in acetonitrile (solvent $\mathrm{B}$ ), as follows: $0-1 \mathrm{~min}, 1-10 \% \mathrm{~B}$; $1-20 \mathrm{~min}, 10-20 \% \mathrm{~B}$; 20-24 min, 20-24\%B, 24-30 min, 24-100\%B, 30-32 min, $100 \% \mathrm{~B} ; 32-33 \mathrm{~min}, 100-1 \% \mathrm{~B} ; 33-35 \mathrm{~min}, 1 \% \mathrm{~B}$. The sample injection volume was $20 \mu \mathrm{L}$, and the solvent flowrate $1 \mathrm{~mL} / \mathrm{min}$. All samples were microfiltered through a $0.22 \mu \mathrm{m}$ syringe filter and stored in dark vials. Quantification of cyanidin-3-O-galactoside, cyanidin-3-O-glucoside, cyanidin-3-O-arabinoside were based on calibration curves created with pure external standards fitted to linear equations $\left(\mathrm{R}^{2}>0.990\right)$. Cyanidin-3- $O$-xyloside was quantified as cyanidin-3-O-glucoside equivalents.

\section{Particle Size Distribution, Total Dissolved Solids and pH}

The particle size distribution of the samples was measured in a LS 13320 Laser Diffraction Particle Size Analyzer (Beckman Coulter, Inc., Krefeld, Germany), and the total dissolved solids were measured as Brix degrees using a digital refractometer (A. Krüss Optronic GmbH, Hamburg, Germany). The $\mathrm{pH}$ was measured using a digital $\mathrm{pH}$ meter equipped with a PHG301 electrode (Radiometer Analytical, Copenhagen, Denmark).

\section{Data Analysis}

Statistical significance $(p<0.05)$ was assessed by one-way analysis of variance (ANOVA) and Tukey's test using IBM SPSS Statistics version 26.

Response surface methodology (RSM) was used to evaluate the effect of the parameters on the extraction of anthocyanins and construct the predictive model. The software Statistica version 13.5 (TIBCO Sofware Inc.) was used to optimize the anthocyanin concentration as well as the total anthocyanin extracted as a function of the extraction temperature, citric acid concentration and liquid-solid ratio. RSM was also used to predict the final $\mathrm{pH}$ and total dissolved solids in the extract. The response surface plots were developed using the fitted quadratic polynomial equations obtained from the regression analysis, changing two variables while the third factor was held at a constant value.

\section{Results and Discussion}

This section describes the optimization of the extraction of anthocyanins from chokeberry juice pomace. First, the total extractable anthocyanin content in the feedstock is quantified using sequential exhaustive extractions in acidified methanol.

The process to be optimized consisted of homogenization and extraction using aqueous citric acid. The duration of the homogenization treatment was selected targeting a constant particle size distribution in the mash. The extractions were performed under different conditions following the experimental design shown in Table 2. The experimental outputs measured were used to construct the empirical model based on response surface methodology. The quadratic equations were then used to assess the influence of the process conditions in the responses, and the optimal conditions were rationalized and discussed from a process-oriented mindset. The selected strategy was finally replicated in the laboratory and compared to the values predicted by the model.

\section{Identification and Quantification of Anthocyanins in Chokeberry Pomace}

Four monoglycosylated anthocyanins were identified in the chokeberry pomace extracts based on their retention time and spectral properties: cyanidin-3-O-galactoside $(62 \%)$, cyanidin-3- $O$-arabinoside (30\%), cyanidin-3- $O$-xyloside (4\%), and cyanidin-3-O-glucoside (2\%). The total anthocyanin content in the pomace was $62.8 \pm 5.5 \mathrm{mg} / \mathrm{g}$ DW (Dry Weight) as measured by exhaustive extraction with acidified 
methanol. This content is taken as a reference for the maximum yield of $100 \%$ Total Anthocyanin Content (TAC) in this feedstock.

The value reported falls towards the higher range of anthocyanin yields reported in Table 1, being in close agreement with the yield reported by Oszmiański and Lachowicz (2016) for the pomace of crushed berries of $66.5 \mathrm{mg} / \mathrm{g}$ DW. The chokeberry juice pomace used in this study had been produced by cold pressing of the berries, which explains the high anthocyanin content left in the waste. Based on this observation, chokeberry juice pomace is confirmed to have great potential as a feedstock for the recovery of anthocyanins, and the optimization of the process is of utmost relevance.

\section{Effect of Homogenization on the Extraction Rate and Extraction Yield}

In this section, extractions were performed with and without homogenization under constant process conditions as follows: aqueous citric acid content $0.75 \%$; temperature $50{ }^{\circ} \mathrm{C}$; and liquid-solid ratio $50 \mathrm{~g}$ solvent/g fresh pomace.

In solid-liquid extractions from plant material, the rate limiting step is the diffusion of the solute from the solid matrix into the extraction solvent [48]. Decreasing the size of the solid particles is one effective way of increasing the contact area between solvent and solid matrix, that typically results in enhanced diffusion, higher extraction rates and reduced extraction times. Figure 1 shows an effective decrease in the size of particles in suspension during homogenization. After 30 min treatment, the distribution converged into a constant median diameter of $\sim 200 \mu \mathrm{m}$, and with $80 \%$ of the particles volume within the range of 150 and $550 \mu \mathrm{m}$ particle diameter. The homogenization treatment resulted in a much faster extraction process. As shown in Fig. 2., conventional extraction with stirring required $45 \mathrm{~min}$ to achieve a constant anthocyanin yield; while the tests with homogenization required only $5 \mathrm{~min}$.

It is important to note that for the homogenization study, the maximum yield was reached before the median particle diameter became constant $(5 \mathrm{~min}$ and $30 \mathrm{~min}$, respectively). Thus, it can be concluded that the particle size reduction obtained in the first 5 min of homogenization was already sufficient to maximize anthocyanin extraction. Despite this observation, further experiments were performed with $30 \mathrm{~min}$ homogenization in order to nullify the possible influence of particle size variations in the observed responses. This decision was made on the basis that prolonged homogenization treatment did not show a detrimental effect on the total anthocyanin extracted, as seen in Fig. 2.

Whereas the homogenization treatment clearly increased the rate of extraction, the overall extraction yield was not affected. The extractions performed with and without homogenization resulted in the same anthocyanin yield of $\sim 41.8 \mathrm{mg} / \mathrm{g} \mathrm{DW}$, which corresponds to $66.5 \%$ of the total content in the raw material, as measured by exhaustive sequential extractions in acidified methanol.
Table 3 Experimental design, independent factors, levels and measured experimental outputs

\begin{tabular}{|c|c|c|c|c|c|c|c|}
\hline \multirow{2}{*}{$\begin{array}{l}\text { Exp } \\
\#\end{array}$} & \multicolumn{3}{|c|}{ Independent factors } & \multicolumn{4}{|c|}{ Experimental outputs } \\
\hline & $\mathrm{CA}(\mathrm{wt} \%)$ & $\mathrm{T}\left({ }^{\circ} \mathrm{C}\right)$ & LSR (g/g) & TAC (mg/g DW) & {$[\mathrm{AC}](\mathrm{mg} / \mathrm{L})$} & TDS $\left({ }^{\circ}\right.$ Brix $)$ & $\mathrm{pH}_{\text {final }}$ \\
\hline 1 & 0.25 & 30 & 20 & $23.6 \pm 1.3$ & $413.1 \pm 24$ & $1.0 \pm 0.1$ & $2.93 \pm 0.02$ \\
\hline 2 & 0.25 & 30 & 80 & $41.8 \pm 1.4$ & $182.9 \pm 6.1$ & $0.4 \pm 0.1$ & $2.77 \pm 0.04$ \\
\hline 3 & 0.25 & 50 & 50 & $41.9 \pm 1.7$ & $288.8 \pm 9.7$ & $0.7 \pm 0.1$ & $2.75 \pm 0.02$ \\
\hline 4 & 0.25 & 70 & 20 & $18.1 \pm 0.2$ & $315.3 \pm 3.6$ & $1.2 \pm 0.1$ & $2.96 \pm 0.01$ \\
\hline 5 & 0.25 & 70 & 80 & $42.6 \pm 2.0$ & $186.6 \pm 8.9$ & $0.4 \pm 0.0$ & $2.76 \pm 0.04$ \\
\hline 6 & 0.75 & 30 & 50 & $41.9 \pm 1.4$ & $295.2 \pm 7.4$ & $0.9 \pm 0.1$ & $2.43 \pm 0.03$ \\
\hline 7 & 0.75 & 50 & 20 & $37.8 \pm 2.4$ & $663.2 \pm 41$ & $1.6 \pm 0.1$ & $2.58 \pm 0.01$ \\
\hline 8 & 0.75 & 50 & 50 & $41.8 \pm 2.5$ & $293.3 \pm 17$ & $1.2 \pm 0.1$ & $2.44 \pm 0.01$ \\
\hline 9 & 0.75 & 50 & 80 & $45.7 \pm 0.3$ & $200.1 \pm 1.8$ & $1.1 \pm 0.1$ & $2.41 \pm 0.01$ \\
\hline 10 & 0.75 & 70 & 50 & $43.8 \pm 1.4$ & $304.8 \pm 13$ & $1.5 \pm 0.1$ & $2.44 \pm 0.02$ \\
\hline 11 & 1.5 & 30 & 20 & $41.0 \pm 2.9$ & $717.9 \pm 51$ & $2.1 \pm 0.1$ & $2.38 \pm 0.05$ \\
\hline 12 & 1.5 & 30 & 80 & $51.0 \pm 1.2$ & $222.6 \pm 5.4$ & $1.5 \pm 0.1$ & $2.26 \pm 0.04$ \\
\hline 13 & 1.5 & 50 & 50 & $46.0 \pm 1.0$ & $322.7 \pm 6.5$ & $1.5 \pm 0.0$ & $2.28 \pm 0.00$ \\
\hline 14 & 1.5 & 70 & 20 & $39.8 \pm 2.9$ & $696.1 \pm 50$ & $2.1 \pm 0.1$ & $2.33 \pm 0.02$ \\
\hline 15 & 1.5 & 70 & 80 & $47.7 \pm 1.6$ & $209.0 \pm 7.5$ & $1.7 \pm 0.1$ & $2.29 \pm 0.00$ \\
\hline
\end{tabular}

LSR liquid-solid ratio, TAC total anthocyanin content, $[A C]$ anthocyanin concentration, TDS total dissolved solids 


\section{Optimization of the Extraction Conditions}

In this study, the extraction of anthocyanins from chokeberry pomace was optimized with regard to total anthocyanin content extracted and anthocyanin concentration in the extract. The parameters selected for the extraction optimization were the following: temperature, liquid-solid ratio and citric acid content in the water. In order to ensure reproducible particle size distribution, all extraction experiments were performed with a homogenization treatment of $30 \mathrm{~min}$. Table 3 shows the independent factors and levels tested, as well as the experimental outputs observed of total anthocyanin content extracted, anthocyanin concentration in the extract, total dissolved solids and final $\mathrm{pH}$ of the extract.

\section{Response Surface Quadratic Model}

The response surface regression model selected was based on second-order quadratic equations, accounting for the relations between the independent factors and the measured output variables total anthocyanin content (TAC, \%), anthocyanin concentration in the extract ([AC], $\mathrm{mg} / \mathrm{L}$ ), final $\mathrm{pH}$ of the extract $\left(\mathrm{pH}_{\text {final }}\right)$ and total dissolved solids (TDS, ${ }^{\circ}$ Brix). Good adjustments were obtained, with regression coefficients $\mathrm{R}^{2}$ of $0.914,0.953,0.994$, and 0.953 for TAC, [AC], $\mathrm{pH}_{\text {final }}$ and TDS, respectively. This model includes the linear, quadratic and interaction effects of the factors and are presented in Eqs. 1-4. The standard error of the calculated coefficients is reported in Supplementary Information.

$$
\begin{aligned}
T A C & =2.18 \times 10^{-2}+0.399(C A)-7.16 \times 10^{-2}(C A)^{2} \\
& +5.11 \times 10^{-3}(T)-6.34 \times 10^{-5}(T)^{2} \\
& +9.83 \times 10^{-3}(L S R)-4.79 \times 10^{-5}(L S R)^{2} \\
& -6.84 \times 10^{-5}(C A \times T)-2.47 \times 10^{-3}(C A \times L S R) \\
& +1.40 \times 10^{-5}(T \times L S R)
\end{aligned}
$$

$$
\begin{aligned}
{[A C]=} & 517.88+466.04(C A)-95.63(C A)^{2} \\
+ & 4.31(T)-6.49 \times 10^{-2}(T)^{2}-15.51(L S R) \\
& -0.117(L S R)^{2}-0.516(C A \times T) \\
& -3.99(C A \times L S R)+2.29 \times 10^{-2}(T \times L S R) \\
p H_{\text {final }} & =3.39-1.09(C A)+0.365(C A)^{2} \\
& -9.31 \times 10^{-4}(T)+9.68 \times 10^{-6}(T)^{2} \\
& -1.10 \times 10^{-2}(L S R)-7.10 \times 10^{-5}(L S R)^{2} \\
& -6.03 \times 10^{-4}(C A \times T)-1.24 \times 10^{-3} \\
& (C A \times L S R)+1.25 \times 10^{-5}(T \times L S R)
\end{aligned}
$$

$$
\begin{aligned}
T D S & =1.10-1.60(C A)-0.491(C A)^{2}+7.45 \times 10^{-4}(T) \\
& +4.93 \times 10^{-5}(T)^{2}-3.07 \times 10^{-2}(L S R) \\
& +1.89 \times 10^{-4}(L S R)^{2}-7.94 \times 10^{-4}(C A \times T) \\
& +2.54 \times 10^{-3}(C A \times L S R)-1.11 \times 10^{-18}(T \times L S R)
\end{aligned}
$$

None of the three factors tested had a significant effect on the total anthocyanin content extracted at a $95 \%$ confidence level. Nevertheless, the highest influence observed was that of the LSR $(p<0.08)$, followed by the synergistic influence of LSR and citric acid $(p<0.08)$. The anthocyanin concentration was mainly influenced by the LSR $(p<0.05)$, with minor influences of the amount of citric acid used $(p<0.06)$ and the temperature $(p<0.07)$. The only significant synergistic effect was that of LSR and citric acid $(p<0.01)$. The total dissolved solids in the extracts were mainly influenced by the amount of citric acid used $(\mathrm{p}<0.00001)$, the LSR $(\mathrm{p}<0.001)$; and the synergy of the two $(\mathrm{p}<0.05)$, as expected. Likewise, the final $\mathrm{pH}$ was also influenced by the citric acid content $(p<0.05)$ and the LSR $(p<0.05)$.

In general, the liquid-solid ratio was the factor with the most significant effect on all the output variables, while the temperature had the least influence. This observation can
Fig. 3 Variation of the percentages of (a) cyanidin-3- $O$-galactoside and (b) cyanidin-3-O-arabinoside in chokeberry extracts produced at 30 and $70{ }^{\circ} \mathrm{C}$ (a)

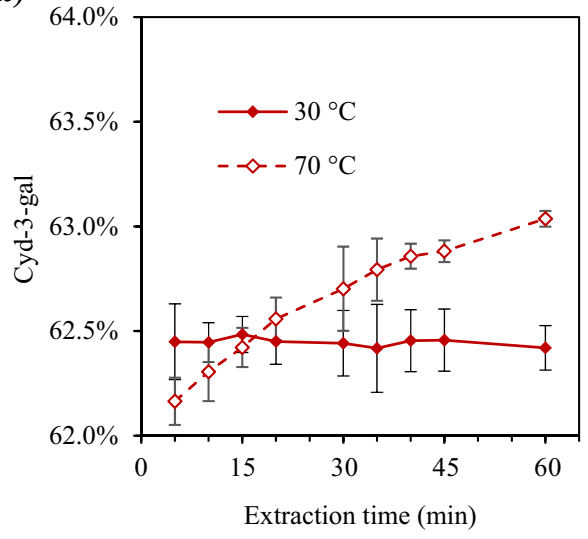

(b)

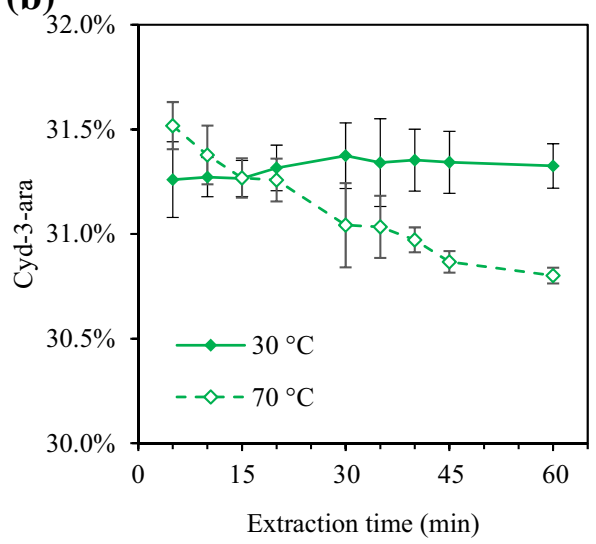



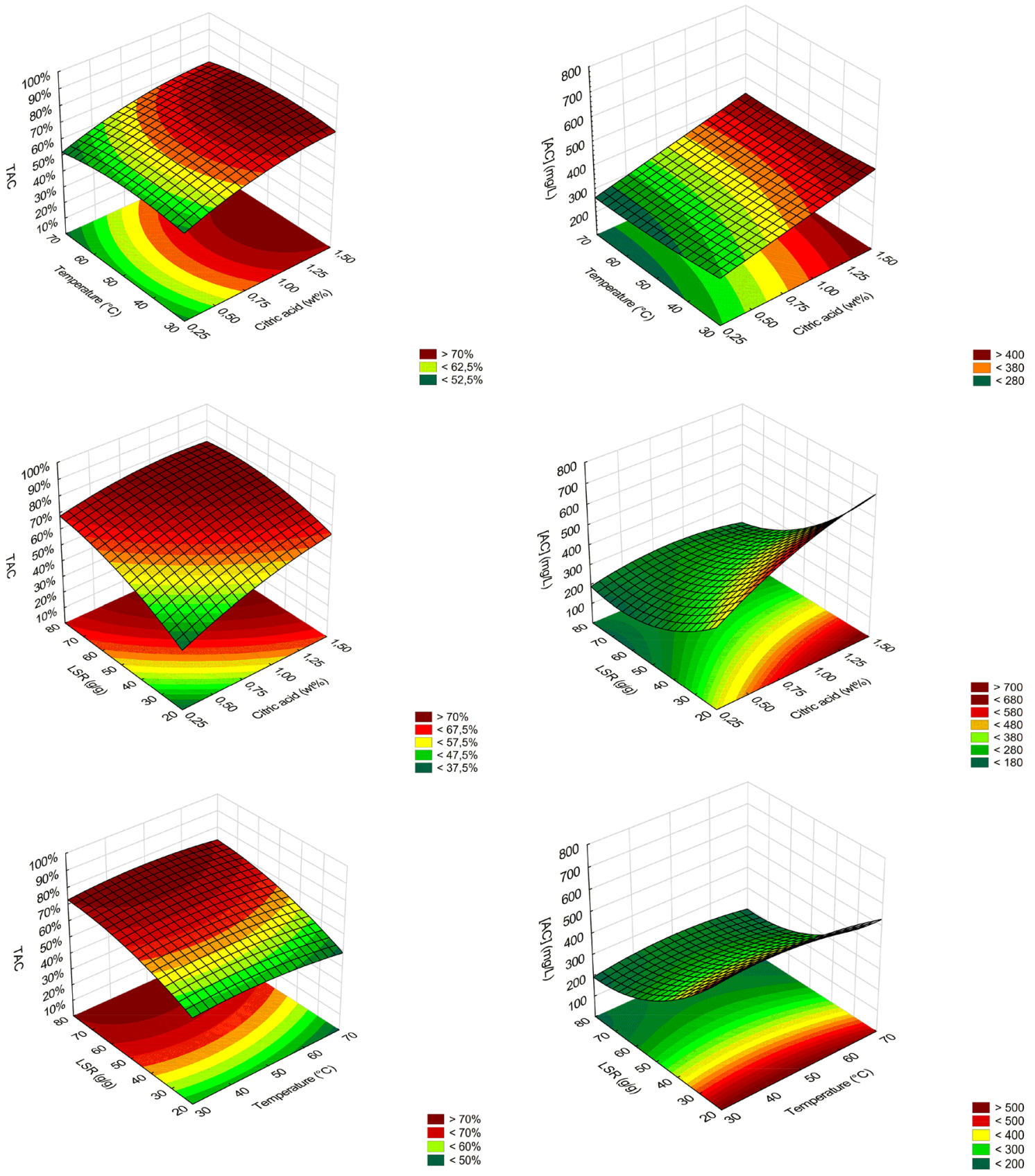

Fig. 4 Response-surface plots showing the effect of the independent factors $\left(\mathrm{T},{ }^{\circ} \mathrm{C}\right.$; CA, wt $\%$; and LSR, g/g) on TAC, \% and [AC], mg/L

be interpreted in two ways; either that the influence of the temperature in the mass transfer was masked by the higher influence of the LSR, or that the increase in anthocyanin extraction was counteracted by degradation. However, with the current empirical model, it is not possible to discern between the two possibilities. In order to identify selective anthocyanin degradation, the profile of products obtained at different temperatures was compared.

\section{Anthocyanin Profile in Extracts Obtained at Different Temperatures}

Selective degradation of given anthocyanins in the extract may not be noticed when comparing the absolute total content extracted. However, selective degradation could undoubtedly affect the proportion of individual anthocyanins in the mixture. 
The effect of temperature on the profile of anthocyanins was investigated at the two ends of the temperature range of interest: 30 and $70{ }^{\circ} \mathrm{C}$, and for a period double the selected extraction time $(60 \mathrm{~min})$. The following process conditions were kept constant: CA: $0.75 \mathrm{wt} \%$ and LSR: $50 \mathrm{~g} / \mathrm{g}$; in order to ensure that the $\mathrm{pH}$ in the extracts was the same $(2.44 \pm 0.01)$ and did not influence the outcome of the stability study. For clarity, the results focus on the two main anthocyanins in chokeberry: cyanidin-3-O-galactoside (cyd-3-gal) and cyanidin-3-O-arabinoside (cyd-3-ara) which combined account for approx. $92 \%$ of the anthocyanins in the extracts.

Figure 3 shows that the proportions of cyd-3-ara and cyd-3-gal during the extractions performed at $30^{\circ} \mathrm{C}$ remain constant for the whole $60 \mathrm{~min}$ period. However, at $70{ }^{\circ} \mathrm{C}$ cyd-3-ara decreases steadily and this is compensated by an increase in the proportion of cyd-3-gal. This observation confirms that the extraction temperature can have an influence, even minor, on the anthocyanin profile. In the scenario with highest temperature $\left(70^{\circ} \mathrm{C}\right)$, the variation in both components was less than $1 \%$ and was not considered a problem for the characteristics of the extract at this or lower temperatures. However, this influence should not be totally neglected, especially when operating at high temperatures or when operating with extracts composed of anthocyanins with different thermal stabilities.

\section{Selection of the Optimal Extraction Conditions}

The optimal set of conditions for the extraction process would be one that maximizes the two responses related to the target product: the TAC and the [AC]. Figure 4 shows

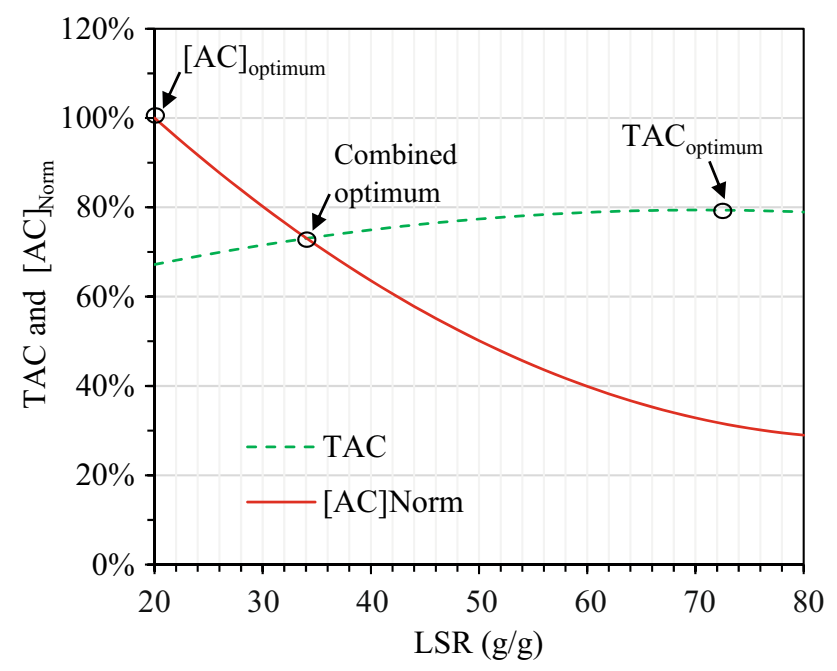

Fig. 5 Variation of the predicted value of TAC and normalized $[\mathrm{AC}]_{\text {Norm }}$ for different liquid-solid ratios (LSR). Constant parameters: T: $45^{\circ} \mathrm{C} ; \mathrm{CA}: 1.5 \mathrm{wt} \%$

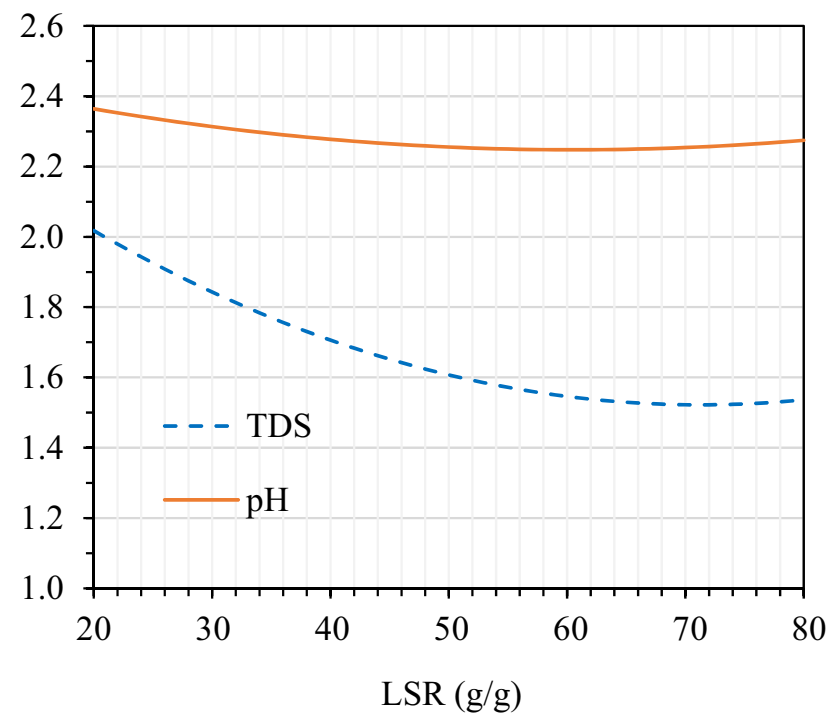

Fig. 6 Variation of the predicted value for total dissolved solids (TDS) and the final $\mathrm{pH}$ of the extract for different liquid-solid ratios (LSR). Constant parameters: T: $45^{\circ} \mathrm{C}$; CA: $1.5 \mathrm{wt} \%$

these two modelled responses as a function of pairs of variables, with the third one being fixed. Both TAC and [AC] are mainly influenced by the LSR. However, increasing LSR results in a higher amount of anthocyanin content extracted (higher TAC), but less concentrated extracts (lower [AC]). In this section, the two responses have been optimized independently and a compromise between the two has been reached for an overall optimal set of conditions.

The individual optimization of TAC provided the optimal parameters of CA: $1.5 \mathrm{wt} \%$; T: $47{ }^{\circ} \mathrm{C}$; and LSR: $71 \mathrm{~g} / \mathrm{g}$, with predicted responses of $79.42 \%$ TAC and $240.7 \mathrm{mg} / \mathrm{L}$ [AC]. This results in an extract concentration that is, however, among the lowest reported in this study. Following this set of experimental conditions, consequent downstream processing into a final product could become costly and inconvenient.

Individual optimization of $[\mathrm{AC}]$ provided the following parameters: CA: $1.5 \mathrm{wt} \%$; $\mathrm{T}: 43{ }^{\circ} \mathrm{C}$; and LSR: $20 \mathrm{~g} / \mathrm{g}$. Whereas $\mathrm{CA}$ and $\mathrm{T}$ were in close agreement with the optimal parameters for the TAC separate optimization, the optimal LSR of $20 \mathrm{~g} / \mathrm{g}$ was, in this case, the lowest of the range studied (20-80); resulting in a somewhat lower TAC of $67.26 \%$, but overall largest $[\mathrm{AC}]$ of $737.3 \mathrm{mg} / \mathrm{L}$.

In order to truly optimize the recovery method from a process-oriented perspective, a cost-effective analysis would need to consider not only the economy of the extraction process, but also the eventual product downstream purification. The choice of downstream unit operations will depend on the product formulation targeted in terms of product design. For instance, if the process envisions a final drying step, a moderate increase in TAC due to large solvent usage would 
Table 4 Overview of the observed and predicted responses for the set of conditions CA: $1.5 \mathrm{wt} \%$; T: $45^{\circ} \mathrm{C}$, LSR: $34 \mathrm{~g} / \mathrm{g}$

\begin{tabular}{lcrl}
\hline Output & $\begin{array}{l}\text { Experimental } \\
\text { response }^{\mathrm{a}}\end{array}$ & Predicted value $^{\mathrm{b}}$ & Rel. error (\%) \\
\hline $\mathrm{TAC}, \%$ & $70.62 \pm 2.99$ & $73.03 \pm 4.03$ & 3 \\
[AC], mg/L & $456.7 \pm 19.3$ & $539.2 \pm 40.4$ & 18 \\
$\mathrm{TDS}, \mathrm{Brix}$ & $1.7 \pm 0.1$ & $1.8 \pm 0.12$ & 5 \\
$\mathrm{pH}_{\text {final }}$ & $2.19 \pm 0.02$ & $2.30 \pm 0.02$ & 7 \\
\hline
\end{tabular}

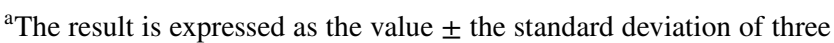
individual replicates

${ }^{\mathrm{b}}$ The result is expressed as the predicted value \pm the standard error of the prediction

probably not justify the high cost of concentration and evaporation associated to it, and an optimum LSR value should be allocated. In the case of other separation technologies like filtration, membrane distillation or molecular distillation, the extract volume to be treated will undoubtedly influence the dimensioning of the equipment as well as the operating costs. Adsorption-desorption processes, on the other hand, are not that much concerned with the LSR, since the product is selectively adsorbed in a solid phase and then desorbed in a new liquid stream of known volume. In the particular case of chokeberry anthocyanins, the solvent of choice in adsorption-desorption processes is an organic solvent [49, 50]. Even if this research work is focused on the extraction unit operation, the authors would like to emphasize the importance of a good synergy between the extraction process, downstream processing and product design.

Given the scope of this study and since information about the economy of downstream alternatives was not available to the authors at present time, both outputs TAC and [AC] were given equal weight in the optimization. For this reason, [AC] was normalized to the highest [AC] reported in this study and is hence expressed as $[\mathrm{AC}]_{\text {Norm }}(\%)$.

Figure 5 shows the variation of TAC and $[\mathrm{AC}]_{\text {Norm }}$ as a function of LSR in the range studied, being the citric acid content and temperature fixed to $1.5 \%$ and $45^{\circ} \mathrm{C}$, respectively. The individual optimums obtained from the model are shown as $\mathrm{TAC}_{\text {optimum }}$ and $[\mathrm{AC}]_{\text {optimum }}$ at 71 and $20 \mathrm{LSR}$, respectively.

The intersection of the two lines provides the overall combined optimum for the two outputs at an LSR value of $34 \mathrm{~g} / \mathrm{g}$. In a similar manner, Fig. 6 shows the predicted variation of $\mathrm{pH}$ and TDS also as a function of LSR. Even though the total dissolved solids and final $\mathrm{pH}$ were not prioritized in the optimization, these parameters have a strong influence on the characteristics of the product. First, the acidity level is of paramount importance for anthocyanin stability both during processing or storage [51]. Because of this, all extractions performed in this study had $\mathrm{pH}$ values equal or below 3.0, which is a reasonable threshold for acceptable anthocyanin preservation. On the other hand, the amount of total dissolved solids influences the anthocyanin concentration in the extract on dry basis, which is related to its purity. Furthermore, downstream processing may need to accommodate the characteristics of the extract in terms of desired TDS and acidity to given applications as a food ingredient or supplement.

The combined optimization reported in this study presents a set of operation conditions that results in a compromise between the total component extracted and extract concentration. The mathematical model developed can be used as a predictive tool to establish relations between conditions and responses, and thus aid in the selection of optimal processing conditions for a given application in terms of product yield and composition.

\section{Validation of the Model}

The combined optimal set of conditions selected (CA: $1.5 \mathrm{wt} \%$, $\mathrm{T}: 45^{\circ} \mathrm{C}$, LSR $34 \mathrm{~g} / \mathrm{g}$ ) was replicated in the laboratory in order to validate the model. The experimental results were compared with the predicted output variables, as shown in Table 4. In all cases, the experimental values were slightly lower than those provided by the model. TAC, TDS and $\mathrm{pH}_{\text {final }}$ were predicted with a relative error $<10 \%$, whereas for the anthocyanin concentration the relative error was of $18 \%$, which is in agreement with the larger standard error of the predicted value.

\section{Conclusion}

This research work presents the extraction of anthocyanins from chokeberry pomace as a case study for process optimization. The total anthocyanin content extracted and anthocyanin concentration in the extract were optimized using response surface methodology. The most influential factors were in both cases the liquid-solid ratio followed by the citric acid content in the solvent. The optimal conditions that maximized both outputs were the following: $1.5 \mathrm{wt} \%$ citric acid, $45{ }^{\circ} \mathrm{C}$ and $34 \mathrm{~g}$ solvent/g pomace. The optimized set of conditions was validated in the laboratory, resulting in $71 \pm 3 \%$ of total anthocyanin content extracted, and an anthocyanin concentration in the final extract of $456.7 \pm 19 \mathrm{mg} / \mathrm{L}$. The experimental results observed for the optimal conditions deviated from the calculated outputs by a relative error lower than $10 \%$ for TAC, TDS and $\mathrm{pH}_{\text {final }}$, and of $18 \%$ for the anthocyanin concentration.

An optimized extraction process is the first stone laid towards the building of a successful recovery process for a given feedstock. In this study, a compromise between total component extracted and extract concentration has been reached. However, economic considerations including the cost of downstream processing need to be taken into account in order to locate the optimal parameter conditions in an 
eventual cost-effective production. Nevertheless, the model developed in this study can be used as a prediction tool for the characteristics of chokeberry extracts produced by acidified water extraction, that can hopefully bring more attention to by-products or biowaste as renewable sources for the sustainable production of high-value products.

Acknowledgements This work was supported by Grønt Udviklings og Demonstrations Program (GUPD) from Miljøstyrelsen in Denmark under the project ProBioFa [J. nr. 34009-18-1358] and the European Union's Horizon 2020 research and innovation program under Marie Skłodowska-Curie [grant agreement No 778168].

\section{References}

1. Ghosh, N., Sen, C.K.: The promise of dietary supplements: research rigor and marketing claims. Nutrition and Enhanced Sports Performance, pp. 759-766. Elsevier, Amsterdam (2019)

2. McCarty, M.F., DiNicolantonio, J.J.: Nutraceuticals have potential for boosting the type 1 interferon response to RNA viruses including influenza and coronavirus. Prog. Cardiovasc. Dis. (2020). https://doi.org/10.1016/j.pcad.2020.02.007

3. Pendyala, B., Patras, A.: In silico screening of food bioactive compounds to predict potential Inhibitors of COVID-19 Main protease (Mpro) and RNA-dependent RNA polymerase (RdRp). (2020). Chemrix. DOI: 10.26434/chemrxiv.12051927.v1

4. Market Research Report. Europe Nutrition and Supplements Market Size, Share \& Trend Analysis Report, By Function, by Formulation, By Consumer, By Distribution Channel, By Region and Segment Forecasts, 2018-2025. https://www.grandviewresear ch.com/industry-analysis/europe-nutrition-supplements-market

5. Statistica. Total U.S. dietary supplements market size from 2016 to 2014. https://www.statista.com/statistics/828481/total-dietarysupplements-market-size-in-the-us/

6. Banerjee, J., Singh, R., Vijayaraghavan, R., MacFarlane, D., Patti, A.F., Arora, A.: Bioactives from fruit processing wastes: green approaches to valuable chemicals. Food Chem. 225, 10-22 (2017)

7. Kumar, K., Yadav, A.N., Kumar, V., Vyas, P., Dhaliwal, H.S.: Food waste: a potential bioresource for extraction of nutraceuticals and bioactive compounds. Bioresourc. Bioprocess. 4(1), 18 (2017)

8. Deng, G.-F., Shen, C., Xu, X.-R., Kuang, R.-D., Guo, Y.-J., Zeng, L.-S., Gao, L.-L., Lin, X., Xie, J.-F., Xia, E.-Q.: Potential of fruit wastes as natural resources of bioactive compounds. Int. J. Mol. Sci. 13(7), 8308-8323 (2012)

9. Fava, F., Totaro, G., Diels, L., Reis, M., Duarte, J., Carioca, O.B., Poggi-Varaldo, H.M., Ferreira, B.S.: Biowaste biorefinery in Europe: opportunities and research \& development needs. New Biotechnol. 32(1), 100-108 (2015)

10. Lin, C.S.K., Pfaltzgraff, L.A., Herrero-Davila, L., Mubofu, E.B., Abderrahim, S., Clark, J.H., Koutinas, A.A., Kopsahelis, N., Stamatelatou, K., Dickson, F.: Food waste as a valuable resource for the production of chemicals, materials and fuels Current situation and global perspective. Energy Environ. Sci. 6(2), 426-464 (2013)

11. Madeddu, C., Roda-Serrat, M.C., Christensen, K.V., El-Houri, R.B., Errico, M.: A biocascade approach towards the recovery of high-value natural products from biowaste: state-of-art and future trends. Waste Biomass Valoriz. (2020)

12. Galanakis, C.M.: Recovery of high added-value components from food wastes: conventional, emerging technologies and commercialized applications. Trends Food Sci. Technol. 26(2), 68-87 (2012). https://doi.org/10.1016/j.tifs.2012.03.003
13. Majerska, J., Michalska, A., Figiel, A.: A review of new directions in managing fruit and vegetable processing by-products. Trends Food Sci Technol 88, 207-218 (2019)

14. Rousseau, J.: Ethnobotanique abénakise. Arch Folklore 11, 145$182(1947)$

15. Rugină, D., Diaconeasa, Z., Coman, C., Bunea, A., Socaciu, C., Pintea, A.: Chokeberry anthocyanin extract as pancreatic $\beta$-cell protectors in two models of induced oxidative stress. Oxid. Med. Cell. Longev. 2015, 429075 (2015)

16. Olas, B., Kedzierska, M., Wachowicz, B., Stochmal, A., Oleszek, W., Jeziorski, A., Piekarski, J., Glowacki, R.: Effect of aronia on thiol levels in plasma of breast cancer patients. Cent. Eur. J. Biol. 5(1), 38-46 (2010)

17. Zapolska-Downar, D., Bryk, D., Małecki, M., Hajdukiewicz, K., Sitkiewicz, D.: Aronia melanocarpa fruit extract exhibits antiinflammatory activity in human aortic endothelial cells. Eur. J. Nutr. 51(5), 563-572 (2012)

18. Handeland, M., Grude, N., Torp, T., Slimestad, R.: Black chokeberry juice (Aronia melanocarpa) reduces incidences of urinary tract infection among nursing home residents in the long term-a pilot study. Nutr. Res. 34(6), 518-525 (2014)

19. Kardum, N., Milovanović, B., Šavikin, K., Zdunić, G., Mutavdžin, S., Gligorijević, T., Spasić, S.: Beneficial effects of polyphenolrich chokeberry juice consumption on blood pressure level and lipid status in hypertensive subjects. J. Med. Food 18(11), 1231$1238(2015)$

20. Badescu, M., Badulescu, O., Badescu, L., Ciocoiu, M.: Effects of Sambucus nigra and Aronia melanocarpa extracts on immune system disorders within diabetes mellitus. Pharmaceutical Biology 53(4), 533-539 (2015)

21. Sidor, A., Gramza-Michałowska, A.: Black chokeberry Aronia melanocarpa L.: a qualitative composition, phenolic profile and antioxidant potential. Molecules 24(20), 3710 (2019)

22. Denev, P.N., Kratchanov, C.G., Ciz, M., Lojek, A., Kratchanova, M.G.: Bioavailability and antioxidant activity of black chokeberry (Aronia melanocarpa) polyphenols: in vitro and in vivo evidences and possible mechanisms of action: a review. Compr. Rev. Food Sci. Food Saf. 11(5), 471-489 (2012)

23. Kapci, E., Cizková, H., Voldrich, M., Rajchl, A., Capanoglu, E.: Investigating the antioxidant potential of chokeberry (Aronia melanocarpa) products. J. Food Nutr. Res. 52(4), 219-229 (2013)

24. Brazdauskas, T., Montero, L., Venskutonis, P.R., Ibanez, E., Herrero, M.: Downstream valorization and comprehensive twodimensional liquid chromatography-based chemical characterization of bioactives from black chokeberries (Aronia melanocarpa) pomace. J. Chromatogr. A 1468, 126-135 (2016). https://doi. org/10.1016/j.chroma.2016.09.033

25. Kitrytė, V., Kraujalienè, V., Šulniūtè, V., Pukalskas, A., Venskutonis, P.R.: Chokeberry pomace valorization into food ingredients by enzyme-assisted extraction: process optimization and product characterization. Food Bioprod. Process. 105, 36-50 (2017). https ://doi.org/10.1016/j.fbp.2017.06.001

26. Grunovaitè, L., Pukalskienè, M., Pukalskas, A., Venskutonis, P.R.: Fractionation of black chokeberry pomace into functional ingredients using high pressure extraction methods and evaluation of their antioxidant capacity and chemical composition. J. Funct. Foods 24, 85-96 (2016). https://doi.org/10.1016/j.jff.2016.03.018

27. Bridle, P., Timberlake, C.: Anthocyanins as natural food coloursselected aspects. Food Chem. 58(1-2), 103-109 (1997)

28. He, J., Giusti, M.M.: Anthocyanins: natural colorants with healthpromoting properties. Annu. Rev. Food Sci. Technol. 1, 163-187 (2010)

29. Vagiri, M., Jensen, M.: Influence of juice processing factors on quality of black chokeberry pomace as a future resource for colour extraction. Food Chem. 217, 409-417 (2017). https://doi. org/10.1016/j.foodchem.2016.08.121 
30. Oszmiański, J., Lachowicz, S.: Effect of the production of dried fruits and juice from chokeberry (Aronia melanocarpa L.) on the content and antioxidative activity of bioactive compounds. Molecules 21(8), 1098 (2016)

31. Oszmiański, J., Wojdylo, A.: Aronia melanocarpa phenolics and their antioxidant activity. Eur. Food Res. Technol. 221(6), 809$813(2005)$

32. D’Alessandro, L.G., Dimitrov, K., Vauchel, P., Nikov, I.: Kinetics of ultrasound assisted extraction of anthocyanins from Aronia melanocarpa (black chokeberry) wastes. Chem. Eng. Res. Des. 92(10), 1818-1826 (2014)

33. Sady, S., Matuszak, L., Błaszczyk, A.: Optimisation of ultrasonic-assisted extraction of bioactive compounds from chokeberry pomace using response surface methodology. Acta Sci. Polon. Technol. Aliment. 18(3), 249-256 (2019)

34. Sójka, M., Kołodziejczyk, K., Milala, J.: Polyphenolic and basic chemical composition of black chokeberry industrial by-products. Ind. Crops Prod. 51, 77-86 (2013). https://doi. org/10.1016/j.indcrop.2013.08.051

35. Dulf, F.V., Vodnar, D.C., Dulf, E.-H., Diaconeasa, Z., Socaciu, C.: Liberation and recovery of phenolic antioxidants and lipids in chokeberry (Aronia melanocarpa) pomace by solid-state bioprocessing using Aspergillus niger and Rhizopus oligosporus strains. LWT 87, 241-249 (2018)

36. Halász, K., Csóka, L.: Black chokeberry (Aronia melanocarpa) pomace extract immobilized in chitosan for colorimetric $\mathrm{pH}$ indicator film application. Food Pack. Shelf Life 16, 185-193 (2018)

37. Woźniak, Ł., Marszałek, K., Skąpska, S., Jędrzejczak, R.: The application of supercritical carbon dioxide and ethanol for the extraction of phenolic compounds from chokeberry pomace. Appl. Sci. 7(4), 322 (2017)

38. Sui, X.: Changes in the color, chemical stability and antioxidant capacity of thermally treated anthocyanin aqueous solution over storage. Impact of Food Processing on Anthocyanins, pp. 49-65. Springer, Berlin (2017)

39. Maurício, E.M., Rosado, C., Duarte, M.P., Fernando, A.L., DíazLanza, A.M.: Evaluation of industrial sour cherry liquor wastes as an ecofriendly source of added value chemical compounds and energy. Waste Biomass Valoriz. 10, 1-10 (2018)

40. Ekici, L., Simsek, Z., Ozturk, I., Sagdic, O., Yetim, H.: Effects of temperature, time, and $\mathrm{pH}$ on the stability of anthocyanin extracts: Prediction of total anthocyanin content using nonlinear models. Food Anal. Methods 7(6), 1328-1336 (2014)
41. Howard, L.R., Brownmiller, C., Prior, R.L., Mauromoustakos, A.: Improved stability of chokeberry juice anthocyanins by $\beta$-cyclodextrin addition and refrigeration. J. Agric. Food Chem. 61(3), 693-699 (2013)

42. Ciriminna, R., Meneguzzo, F., Delisi, R., Pagliaro, M.: Citric acid: emerging applications of key biotechnology industrial product. Chem. Cent. J. 11(1), 22 (2017)

43. Vinatoru, M., Mason, T., Calinescu, I.: Ultrasonically assisted extraction (UAE) and microwave assisted extraction (MAE) of functional compounds from plant materials. Trends Anal. Chem. 97, 159-178 (2017)

44. Plaza, M., Turner, C.: Pressurized hot water extraction of bioactives. Trends Anal. Chem. 71, 39-54 (2015)

45. Yan, L.-G., He, L., Xi, J.: High intensity pulsed electric field as an innovative technique for extraction of bioactive compounds: a review. Crit. Rev. Food Sci. Nutr. 57(13), 2877-2888 (2017)

46. Nadar, S.S., Rao, P., Rathod, V.K.: Enzyme assisted extraction of biomolecules as an approach to novel extraction technology: a review. Food Res. Int. 108, 309-330 (2018)

47. Dinkova, R., Heffels, P., Shikov, V., Weber, F., Schieber, A., Mihalev, K.: Effect of enzyme-assisted extraction on the chilled storage stability of bilberry (Vaccinium myrtillus L.) anthocyanins in skin extracts and freshly pressed juices. Food Res. Int. 65, 35-41 (2014)

48. Pinelo, M., Sineiro, J., Núñez, M.A.J.: Mass transfer during continuous solid-liquid extraction of antioxidants from grape byproducts. J. Food Eng. 77(1), 57-63 (2006)

49. Denev, P., Ciz, M., Ambrozova, G., Lojek, A., Yanakieva, I., Kratchanova, M.: Solid-phase extraction of berries' anthocyanins and evaluation of their antioxidative properties. Food Chem. 123(4), 1055-1061 (2010)

50. Kraemer-Schafhalter, A., Fuchs, H., Pfannhauser, W.: Solid-phase extraction (SPE): a comparison of 16 materials for the purification of anthocyanins from aronia melanocarpa var Nero. J. Sci. Food Agric. 78(3), 435-440 (1998)

51. Moldovan, B., David, L., Chişbora, C., Cimpoiu, C.: Degradation kinetics of anthocyanins from European cranberrybush (Viburnum opulus L.) fruit extracts. Effects of temperature, $\mathrm{pH}$ and storage solvent. Molecules 17(10), 11655-11666 (2012)

Publisher's Note Springer Nature remains neutral with regard to jurisdictional claims in published maps and institutional affiliations.

\section{Affiliations}

\section{Maria Cinta Roda-Serrat ${ }^{1}$. Thalles Allan Andrade ${ }^{1}$ Janus Rindom ${ }^{1}$. Peter Brilner Lund ${ }^{1}$. Birgir Norddahl ${ }^{1}$. Massimiliano Errico ${ }^{1}$}

Maria Cinta Roda-Serrat mcs@kbm.sdu.dk
1 Department of Chemical Engineering, Biotechnology and Environmental Technology, University of Southern Denmark, 5230 Odense M, Denmark 